\title{
Pengembangan Arsitektur Data Sistem Informasi Sekolah
}

\author{
Rizqi Ari Putra1, Muhammad Fahmi Alauddin², Islam Nur Alam³, M. Ainul Yaqin \\ Jurusan Teknik Informatika, Fakultas Sains dan Teknologi \\ Universitas Islam Negeri Maulana Malik Ibrahim Malang \\ Jalan Gajayana No. 50 Malang 65144 Telp. +62 (341) 551-354 \\ 16650079@student.uin-malang.ac.id ${ }^{1}, 16650112 @ s t u d e n t . u i n-m a l a n g . a c . i d^{2}$, \\ 16650096@student.uin-malang.ac.id ${ }^{5}$, yaqinov@ti.uin-malang.ac.id ${ }^{4}$,
}

\begin{abstract}
The purpose of this study is to design a School Information System database architecture based on National School Standards. National School Standards are used as a reference in determining business processes in a school, especially elementary and midle-high school. These processes then describe the entity and its attributes. The database used is a Relational Database so that entities and attributes are drawn as a table that has relationships between entities. To model relationships between entities, use Entity Relational Diagrams. The results of this study are the realization of database architecture with national school standards. This database architecture design is expected to be a reference in building School Information Systems that are in accordance with National School Standards.
\end{abstract}

Keywords: Database, Entity Relationship Diagram, Relational Database, Value Chain

\begin{abstract}
Abstrak
Tujuan penelitian ini adalah untuk merancang arsitektur database Sistem Informasi Sekolah berdasarkan Standar Sekolah Nasional. Standar Sekolah Nasional digunakan sebagai acuan dalam menentukan proses bisnis pada sebuah sekolah, khususnya sekolah dasar dan menengah. Dari prosesproses tersebut kemudian diuraikan entitas dan atributnya. Database yang digunakan adalah Relational Database sehingga entitas dan atribut digambararkan sebagai sebuah tabel yang memiliki relasi antar entitas. Untuk memodelkan relasi antar entitas di gunakan Entity Relational Diagram. Hasil dari penelitian ini adalah terwujudnya arsitektur database yang berstandar sekolah nasaional. Dengan adanya perancangan arsitektur database ini diharapkan dapat menjadi rujukan dalam membangun Sistem Informasi Sekolah yang sesuai dengan Standar Sekolah Nasioanl.
\end{abstract}

Kata kunci: Database, Entity Relational Diagram, Relational Database, Value Chain

\section{PENDAHULUAN}

Teknologi informasi mengalami perkembangan yang pesat. Dengan hadirnya teknologi informasi dapat membantu meningkatkan kinerja. Salah satu sistem informasi yang seakan-akan wajib adalah sistem informasi sekolah. Sistem informasi sekolah mampu menawarkan segala kemudahan baik untuk warga sekolah maupun masyarakat luar. Sebelum melakukan perancangan Sistem Informasi Sekolah perlu dilakukan Analisa dan pemetaan aktivitas-aktivitas terkait di dalamnya. Tujuan dalam pemetaan tersebut selain untuk memudahkan dalam melakukan perancangan database juga berguna untuk melihat aktivitas mana yang penting dan menjadi aktivitas utama. Agar Sistem Informasi Sekolah yang dibangun memeliki standar perlu dilakukan standarisasi. Salah satu standar yang ada di Indonesia adalah Sekolah Standar Nasional. Standar ini membahas baik Standar Kompetensi Lulusan, Standar Isi, Standar Proses, Standar Pendidikan dan 
Tenaga Kependidikan, Standar Sarana dan Prasarana, Standar Pengelolaan, Standar Pembiayaan Pendidikan dan Standar Penilaian Pendidikan.

Perancangan sistem informasi sekolah tidak dapat dilakukan sembarangan, perlu adanya pemikiran yang matang. Salah satu bagian yang harus direncanakan adalah Arsitektur Data pada sistem sekolah. Arsitektur data menggambarkan suatu entitas dan bagaimana data di dalamnya berpindah dan saling memiliki hubungan antara data satu dengan data lain. perencanaan yang buruk pada Arsitektur Data dapat mengakibatkan sulitnya melakukan pengembangan sistem pada masa yang akan mendatang. Untuk itu pada penelitian inin dilakukan perancangan Arsitektur Data Sistem Informasi Sekolah Dengan Menerapkan Sekolah Standar Nasional.

Pada penelitian [1] yang merancang sistem informasi akademik sekolah, perancangan sistemnya menggunakan Activity Diagram dan Entity Relationship Diagram (ERD). Pada perancangan sistem informasi akademik sekolah tersebut terdapat satu database dan memiliki enam tabel yang digunakan yaitu :
a) Tabel Guru
b) Tabel Siswa
c) Tabel Jadwal Siswa
d) Tabel Kelas
e) Tabel Pelajaran
f) Tabel Nilai

Dan pada penelitian lainnya, [2] perancangan sistemnya sama dengan penelitian diatas yang menggunakan Activity Diagram dan ERD. Sementara database yang digunakan untuk membangun sistem informasi akademik sekolah pada penelitian tersebut memiliki tujuh tabel yaitu :

a) Tabel Siswa

b) Tabel Kelas Siswa

c) Tabel Kelas

d) Tabel Nilai

e) Tabel Mapel

f) Tabel Guru

g) Tabel Jawal

Terlihat pada dua penelitian diatas yang membangun perancangan database sisten informasi sekolah masih belum menggunakan Standar Sekolah Nasional (SSN). Kebanyakan sekolah membuat sistem informasi hannya berfokus pada akademik saja, yang dimana perancangan sistem informasi seperti ini masih belum mencapai SSN yang diinginkan oleh pemerintah. Oleh karena itu penelitian ini bertujuan sebagai referensi sekolah-sekolah yang ada di Indonesia agar dalam membangun rancangan database sistem informasi sekolah bisa sesuai dengan peraturan pemerintah atau biasa disebut dengan SSN.

\section{METODOLOGI PENELITIAN}

Langkah-langkah yang dilakukan untuk melakukan penelitian ini adalah sebagai mana pada gambar 1 . 


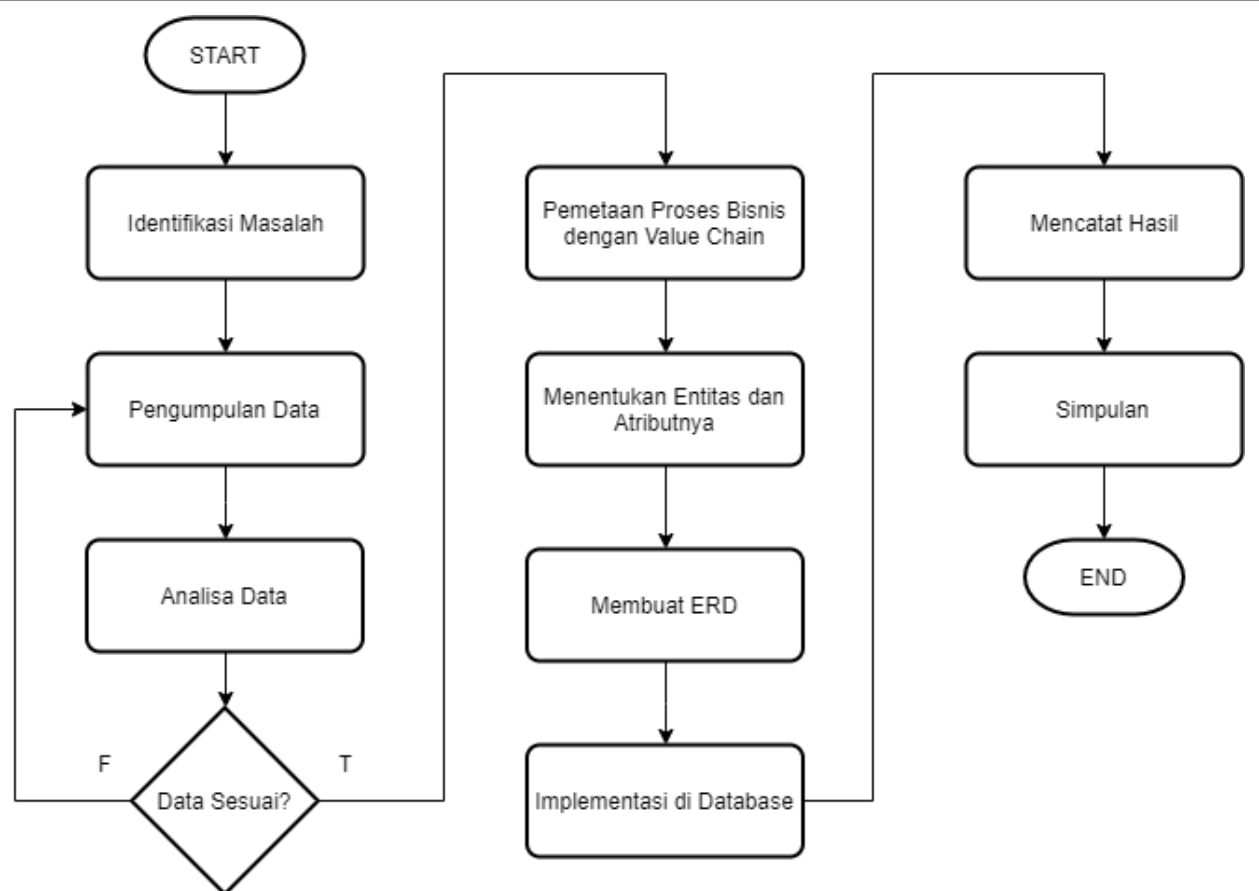

Gambar 1. Metode Penelitian

Langkah pertama yang dilakukan adalah melakukan identifikasi masalah terkait dan melakukan studi pustaka. Selanjutnya adalah melakukan pengumpulan data. Ada dua cara dalam pengumpulan data pada penelitian ini yaitu dengan melakukan observasi proses bisnis yang ada disekolah dan melakukan survei ke sekolah langsung sesuai dengan kebutuhan data. Setelah data terkumpul barulah di analisa apakah data sudah lengkap atau belum, jika belum lengkap maka dilakukan lagi pengumpulan data.

Jika data sudah lengkap maka selanjutnya adalah tahap pemetaan proses bisnis menggunakan kerangka analisa value chain. Kemudian masing-masing proses bisnis yang sudah berhasil dipetakan tadi akan ditentukan entitas dan atributnya. Setelah itu ditentukan relasi dan kardinalitasnya antar entitas.

Langkah selanjutnya adalah implementasi rancangan database tersebut ke dalam database dengan memperhatikan entitas, atribut dan relasi yang ada. Kemudian jika sudah berhasil diimplementasikan perlu dilakukan pencatatan hasil. Langkah terakhir adalah melakukan simpulan terhadap penelitian yang sudah dilakukan.

\subsection{Sistem Informasi Sekolah}

Sistem informasi adalah suatu sistem yang digunakan untuk melihat informasi yang dibutuhkan oleh manusia, dengan tujuan jika suatu kegiatan dilakukan menggunakan sistem informasi akan mempermudah kegiatan manusia tersebut. Hal ini didukung dengan pernyataan [3] dalam bukunya mengatakan, Sistem informasi adalah suatu sistem didalam organisasi yang mendukung operasi, kebutuhan transaksi harian, kegiatan strategi dari suatu organisasi dan bersifat menejerial. Oleh karena itu sistem informasi sekolah sangatlah penting untuk 
mendukung kegiatan belajar mengajar, agar semua kegiatan yang dilakukan di suatu sekolah bisa terorganisasi dengan baik. Sehingga membuat para pegawai sekolah bisa lebih mudah dalam melaksanakan pekerjaannya, dan para siswa bisa lebih nyaman dalam belajar.

\subsection{Entity Relationship Diagram}

Entity Relationship Diagram (ERD) adalah bentuk hubungan suatu kegiatan atau suatu rancangan di dalam sistem yang saling berkaitan satu dengan yang lain dan mempunyai fungsi di dalam proses tersebut. ERD adalah pemodelan basis data relasional yang terdiri dari sekumpulan objek yang saling berhubungan satu dengan lainnya. Didalam ERD ini objek disebut dengan entity dan hubungan yang dimiliki setiap entity disebut dengan relationship. Suatu entity memiliki bersifat unik dan memiliki juga atribut sebagai pembeda dengan entity lainnya [4].

\subsection{Value Chain}

Porter (1985) menjelaskan, Analisis value chain merupakan alat kerangka analisa yang digunakan untuk memahami secara lebih baik terhadap keunggulan kompetitif, untuk mengidentifikasi dimana value pelanggan dapat ditingkatkan atau penurunan biaya, dan untuk memahami secara lebih baik hubungan perusahaan dengan pemasok/supplier, pelanggan, dan perusahaan lain dalam industri. [5] Kerangka analisis ini dibagi menjadi dua bagian, aktifitas nilai dan keuntungan/ margin. Aktifitas nilai sendiri dibagi menjadi dua aktifitas yaitu aktifitas utama/ primary activity dan aktifitas pendukung/ support activity. [6] Pada gambar 2 ditunjukkan mengenai kerangka analisa menggunakan value chain.

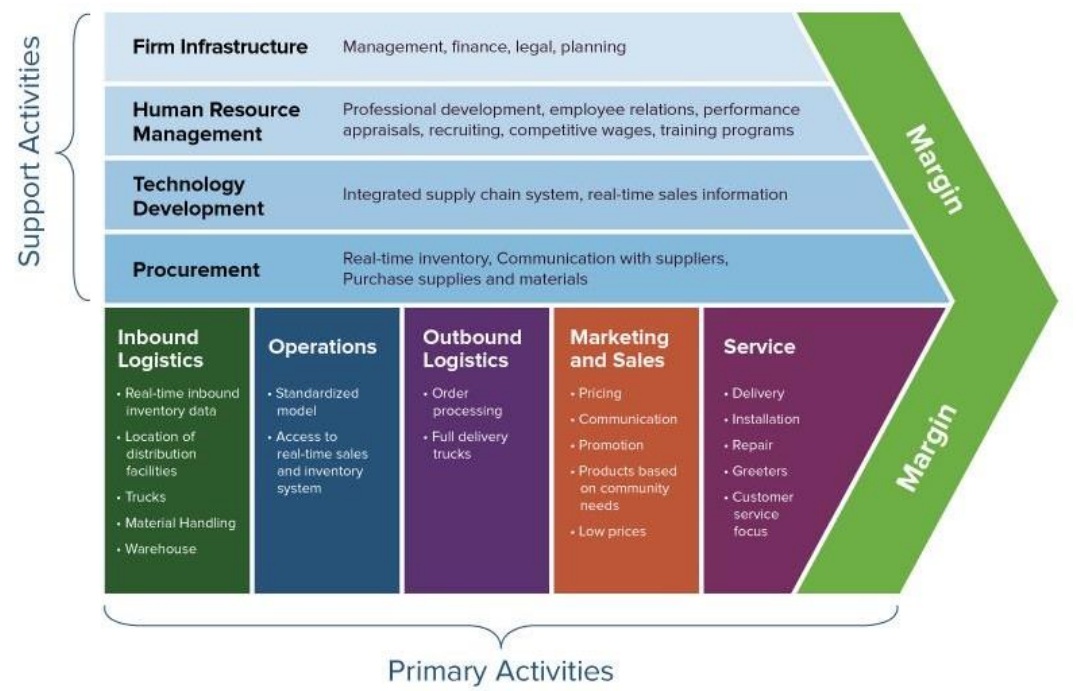

Gambar 2. Analisis Value Chain

\subsection{Standar Nasional Pendidika (SNP)/ Standar Sekolah Nasional (SNS)}

Pendidikan nasional di Indonesia harus sesuai dengan Standar Nasional Pendidikan (SNP), untuk tercapainya pendidikan yang baik. Dengan tujuan untuk membuat anak bangsa Indonesia menjadi cerdas, berakhlak mulia dan produktif. 
Dalam Peraturan Mentri Pendidikan Nasional (PERMEN) Nomor 19 Tahun 2007, dijelaskan bahwa SNP merupakan kriteria minimal dari sistem pendidikan di seluruh wilayah hukum Negara Kesatuan Republik Indonesia. Oleh karena itu SNP ini sangatlah penting untuk diterapkan di setiap sekolah yang ada di negara Indonesia, SNP sendiri meliputi beberapa hal yaitu :

a. Standar Isi

Dalam [7] Glosarium no (4), membahas tentang ruang lingkup materi dan tingkat kompetensi yang digunakan dalam kriteria tentang kompetensi lulusan, mata pelajaran, bahan kajian dan silabus pembelajaran. Kompetensikompetensi tersebut harus bisa dipenuhi oleh setiap peserta didik pada jenjang dan jenis pendidikan tertentu.

b. Standar Proses

Dalam [7] Glosarium no (5), Standar Proses adalah standar nasional untuk pendidikan yang digunakan sebagai standar minimal dalam pelaksanaan pembelajaran pada satu satuan pendidikan di Indonesia untuk mencapai standar kompetensi lulusan. Standar proses tersebut harus dilakukan agar terlaksananya proses pembelajaran yang efektif dan efisien.

c. Standar Kompetensi Lulusan

Standar kompetensi lulusan dalam [7] Glosarium no (3) ini digunakan untuk pedoman penilaian dalam menentukan kelulusan dari peserta didik. Standar Kompetensi Lulusan harus mencakup beberapa hal yang harus dimiliki setiap peserta didik, seperti pengetahuan, sikap, dan keterampilan.

d. Standar Pendidik dan Tenaga Kependidikan

Pada [7] Glosarium no (6), Standar pendidik dan tenaga kependidikan harus memenuhi kriteria pendidikan seperti kelayakan fisik maupun mental dari seorang pendidik, dan seorang pendidik harus memiliki kualifikasi akademik yang bagus dan kompetensi sebagai seorang pendidik

e. Standar Sarana dan Prasarana

Pada [7] Glosarium no (7), menjelaskan tentang standar minimal dari sutuan pendidikan untuk sarana dan prasana yang dibutuhkan agar sesuai dengan standar nasional. Satuan pendidikan harus memiliki ruang belajar, tempat berolahraga, perpustakaan, tempat beribadah, bengkel kerja, laboratorium, tempat bermain, tempat berekreasi dan, berkreasi serta sumber belajar lainnya. Sarana dan prasarana tersebut diperlukan untuk menunjang proses pembelajaran yang berkelanjutan, termasuk penggunaan teknologi informasi dan komunikasi.

f. Standar Pengelolaan

Dalam [7] Glosarium no (2), menjelaskan yang ditujukan untuk satuan pendidikan dasar dan menengah, adalah standar pengelolaan pendidikan nasional untuk sekolah/madrasah harus memeiliki beberapa hal yang wajib dilakukan seperti perencanaan, pelaksanaan, dan pengawasan kegiatan pendidikan. agar bisa tercapainya efisiensi dan efektivitas dalam penyelenggaraan pendidikan. 
g. Standar Pembiayaan

Pembiayaan pendidikan dalam [7] Glosarium no (8), menjelaskan standar yang mengatur komponen dan besarnya biaya operasi bagi peserta didik pada satuan pendidikan yang berlaku selama satu tahun.

h. Standar Penilaian Pendidikan

Standar penilaian pendidikan pada jenjang pendidikan dasar dan menengah dalam [7] Glosarium no (9), terdiri dari tiga aspek yaitu : mekanisme, prosedur, dan instrumen penilaian hasil belajar peserta didik.

\section{HASIL DAN PEMBAHASAN}

Sekolah bisa diandaikan sebagai sebuah perusahaan yang di dalamnya terdapat akuisisi material/ bahan, pemrosesan bahan hingga menjadi bahan jadi serta menyediakan pelayanan/ service. Begitu halnya dengan sekolah, sekolah juga melakukan produksi untuk menghasilkan lulusan yang terbaik dengan menerapkan standar pendidikan nasional di dalam prosesnya. Adapun proses pendidikan sendiri sesuai dengan Peraturan Menteri Pendidikan Nasional Republik Indonesia Nomor 41 Tahun 2007 Pasal 1 Ayat 2 mencakup perencanaan proses pembelajaran, pelaksanaan proses pembelajaran, penilaian hasil pembelajaran, dan pengawasan proses pembelajaran. Dari hasil analisa yang dilakukan diperoleh aktivitas utama dan aktivitas pendukung sebagaimana gambar 3.

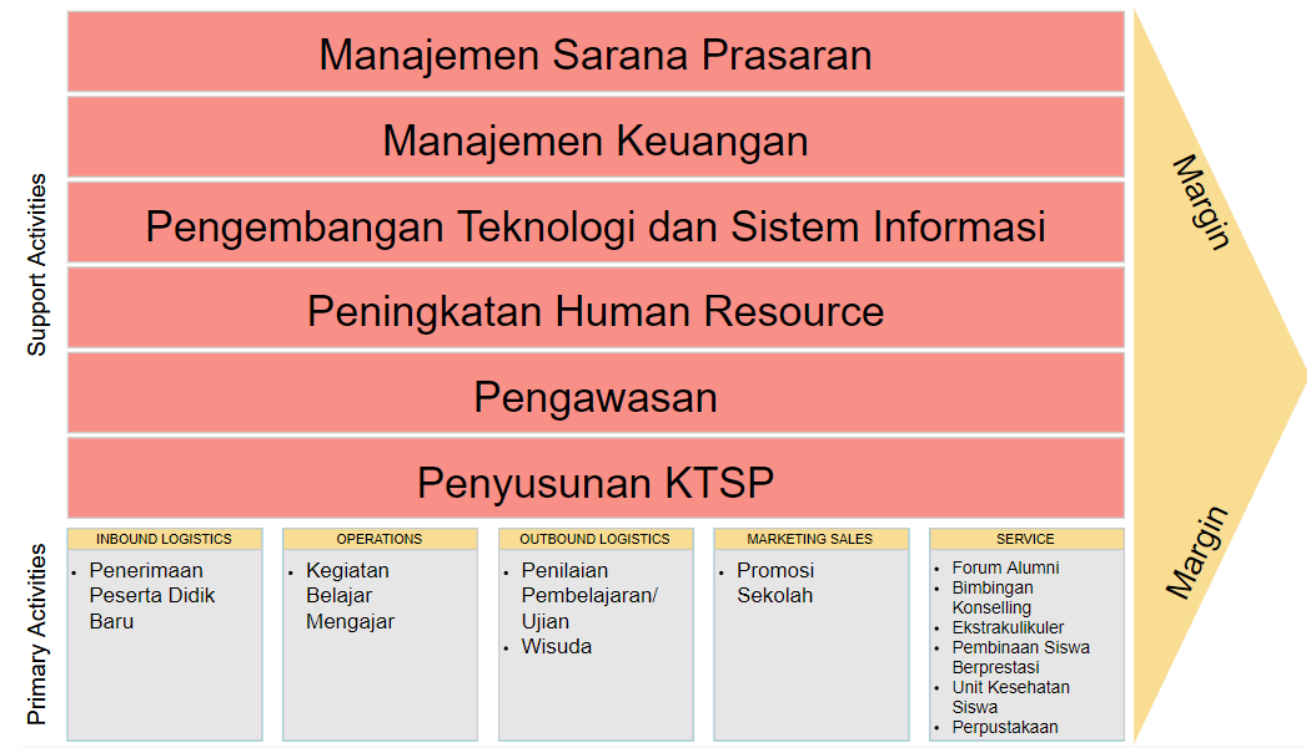

Gambar 3. Analisa Value Chain

Dari analisa proses bisnis yang sudah dilakukan dapat dibuat Entity Relationship Diagram sebagai acuan dalam membangun database system informasi sekolah. Adapun Entity Relationship Diagram yang dibuat adalah sebagai berikut:

a) Inbound Logistic

Aktivitas ini merupakan aktivitas untuk mendapatkan objek untuk diproses. Pada sekolah sendiri siswa bias disebut sebagai objek, karena di dalamnya siswa 
akan diolah melalui proses pembelajaran dan pengembangan lainnya sehingga meghasilkan output yang terjamin. Penerimaan Peserta Didik Baru (PPDB) merupakan aktivitas inbound logistic dalam sekolah. Sesuai dengan Perintah Menteri Perintah Menteri Nomor 19 Tahun 2007, penyusunan dan penetapan petunjuk operasional ditentukan oleh bidang kesiswaan. Adapun ERD dari PPBD adalah ditunjukan oleh gambar 4 .

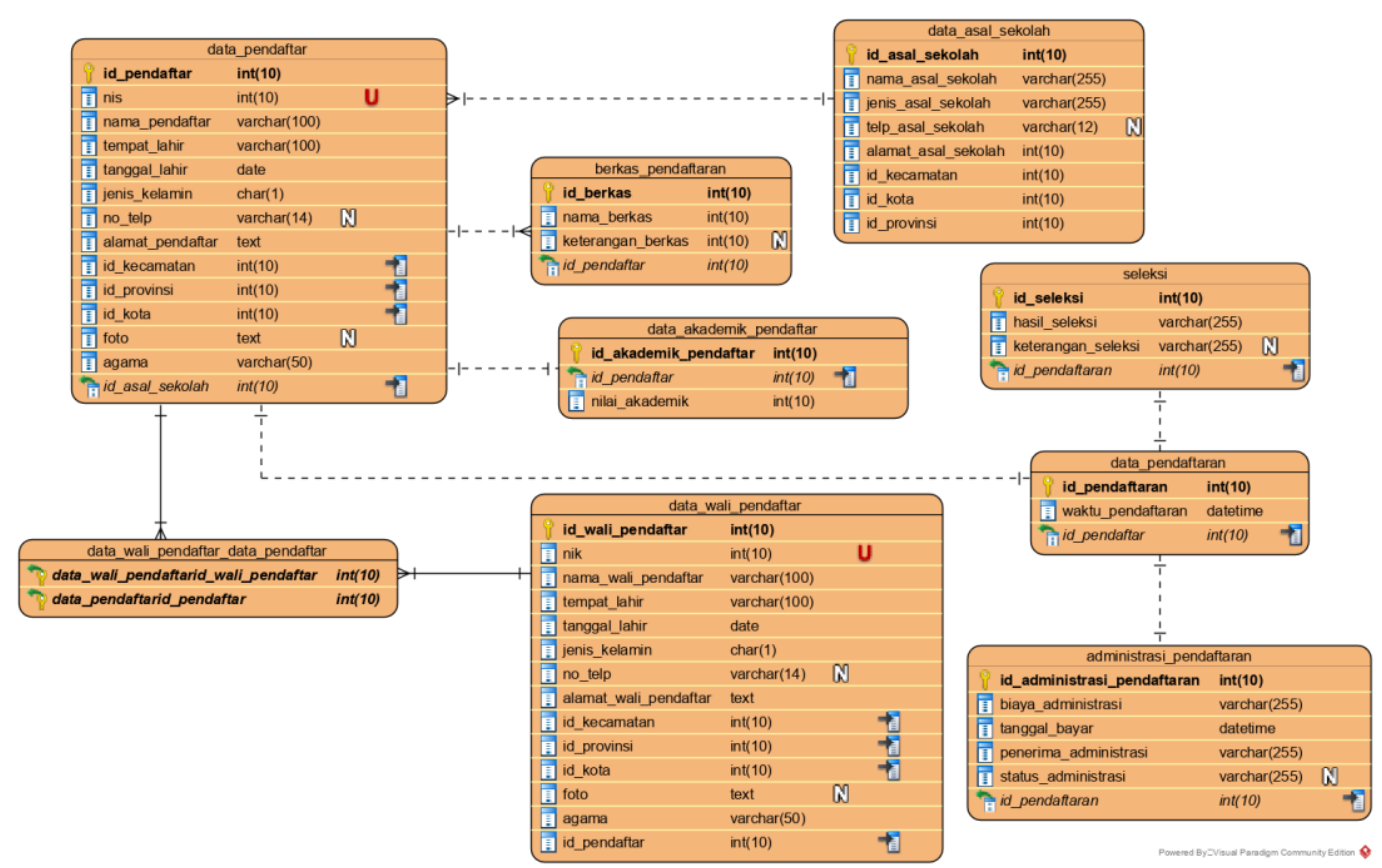

Gambar 4. ERD PPDB

b) Operations

Aktivitas operation bertujuan untuk mengolah murid untuk menjadi lulusan yang bermutu. Dalam sebuah aktivitas operation yang dimaksud adalah Kegaiatan Belajar Mengajar. Proses belajar demgajar harus disesuaikan dengan standar yang telah di tetapkan oleh pemeruintah, adapun standar yang mengatur kegiatan belajar mengajar terdapat dalam Perintah Menteri Nomor 41 Tahun 2007 tentang standar proses. Dari proses KBM bias dibuat menjadi database dengan ERD sebagaimana gambar 5 . 
Jurnal Riset Sistem Informasi Dan Teknik Informatika (JURASIK)

Volume 5 Nomor 2 Agustus, pp 175-186

ISSN: 2527-5771/EISSN: 2549-7839

https://tunasbangsa.ac.id/ejurnal/index.php/jurasik

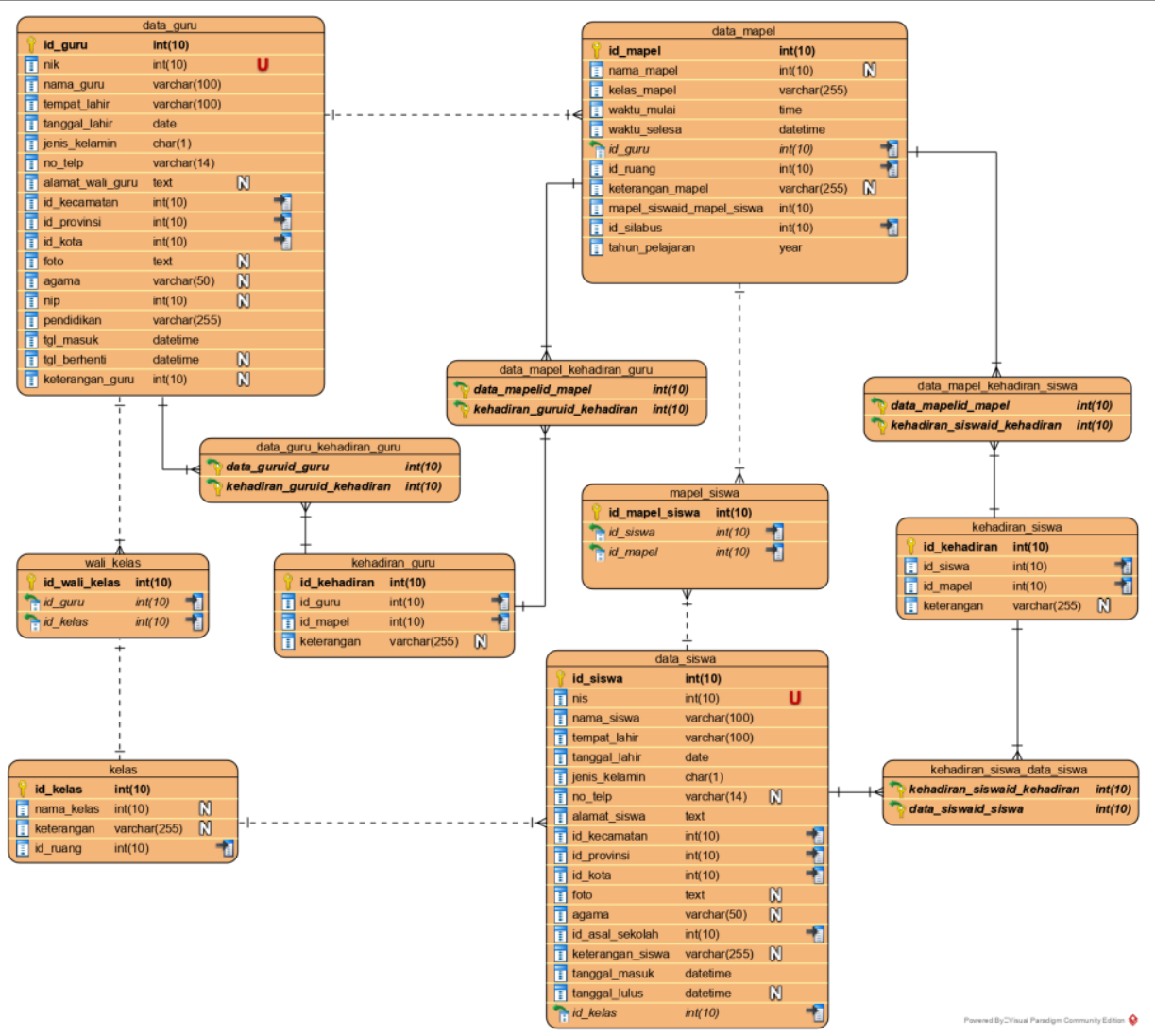

Gambar 5. ERD KBM

\section{c) Outbond Logistics}

Aktivitas ini merupakan salah satu aktivitas penting, karena di dalamnya terdapat evaluasi dari proses operation untuk nantinya bias diketahui apakah proses yang telah dilakukan sudah berhasil atau belum. Dalam sebuah sekolah evaluasi dalam proses KBM adalah dengan adanya ujian. Ujian menjadi penentu bagi siswa apakah sudah sesuai dengan standar yang sudah ditentukan atau belum. Evaluasi dan ujian dibahas pada Perintah Menteri Nomor 41 Tahun 2007 tentang standar proses. Adapun ERD dari proses penilaian siswa sebagaimana gambar 6.

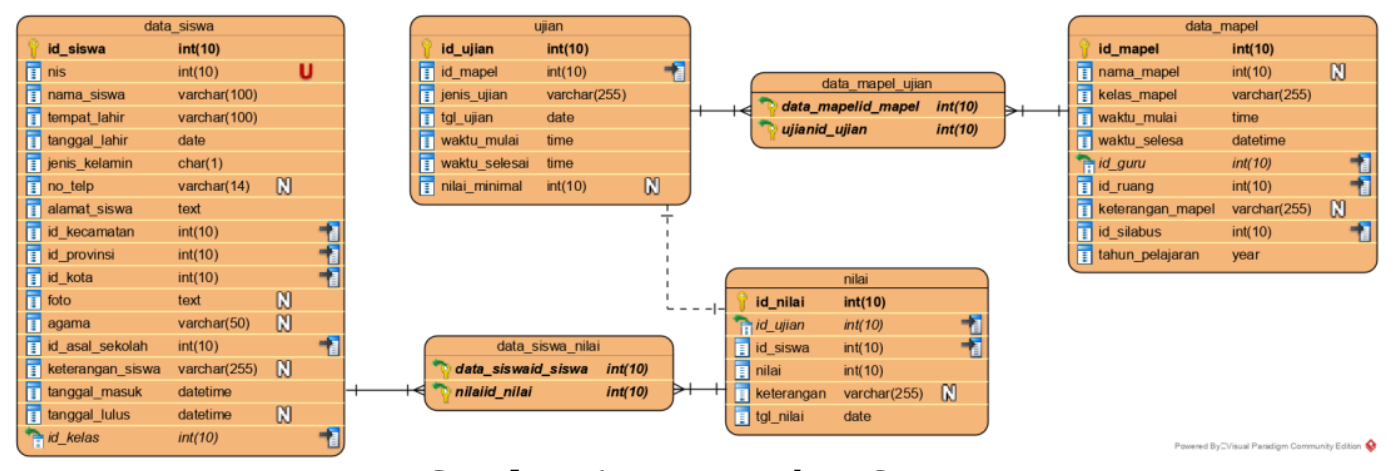

Gambar 6. ERD Penilian Siswa 
d) Service

Aktivitas service merupakan aktivitas yang dilakukan guna mendapatkan output yang lebih baik. Pada aktivitas ini biasaya terdapat pelayan-pelayan yang menjadi wajib dan sudah ditetapkan sebelumnya. Sebagaimana dalam Perintah Menteri Nomor 19 Tahun 2007 tentang standar pengelolaan setidaknya sekolah harus memiliki perpustakaan, bimbingan konseling, extrakurikuler, pembinaan siswa berprestasi dan unit kesehatan sekolah. Pada gambar 7 merupkan ERD dari Unit Kesehatan Sekolah (UKS), UKS perlu dimasukkan dalam system informasi sekolah guna mendata dan melihat kesehatan dari siswa. Layanan perpustakaan menjadi bagian tidak bisa dipisahkan dari sebuah sekolah karena mampu menunjang siswa dalam mencari sumber informasi, adapun ERD dari perpustakaan ditunjukan pada gambar 8. Gambar 9 merupakan ERD dari pelacakan alumni, ini penting karena bisa membantu adik tingkat dalam menentukan pilihan setelah lulus dari lembaga sekolah. Gambar 10 merupakan ERD dari Bimbingan Konseling, salah satu fungsi konseling adalah membantu siswa dalam memecahkan berbagai permasalahan yang dihadapi. Gambar 11 dan 12 masing-masing adalah ERD Ekstrakurikuler dan Bimbingan Siswa Berprestasi, keduanya sangat erat dalam hal pengembangan kemampuan akdemis dan non akedemis siswa.

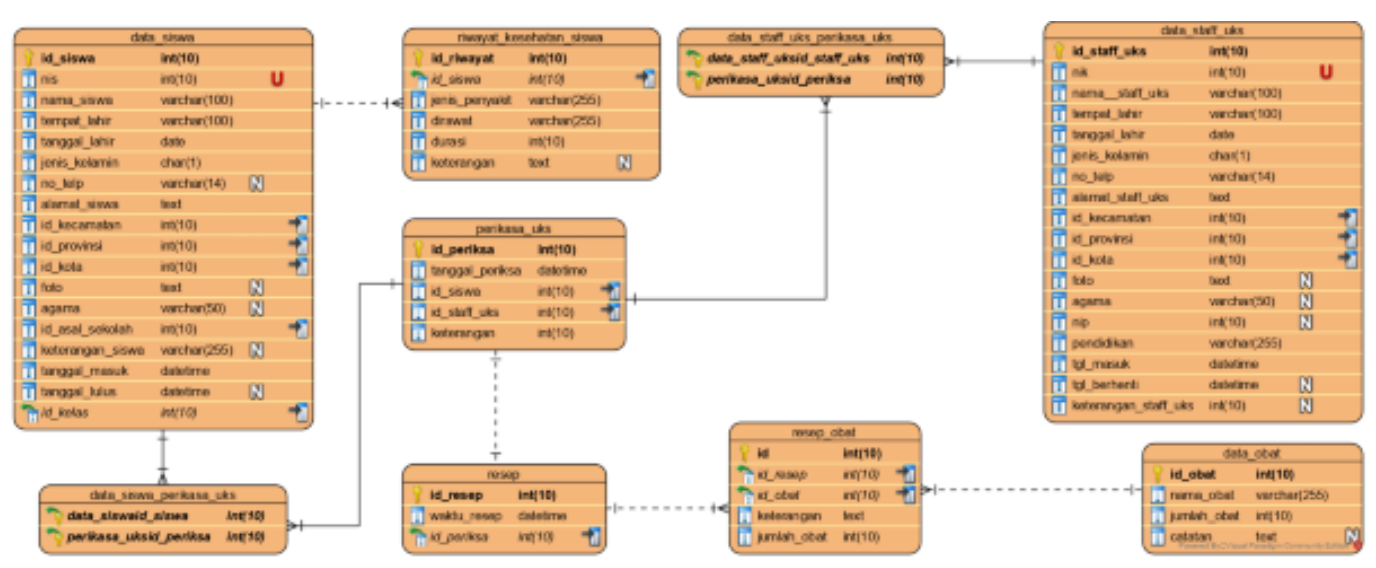

Gambar 7. ERD Unit Kesehatan Sekolah 
Jurnal Riset Sistem Informasi Dan Teknik Informatika (JURASIK)

Volume 5 Nomor 2 Agustus, pp 175-186

ISSN: 2527-5771/EISSN: 2549-7839

https://tunasbangsa.ac.id/ejurnal/index.php/jurasik

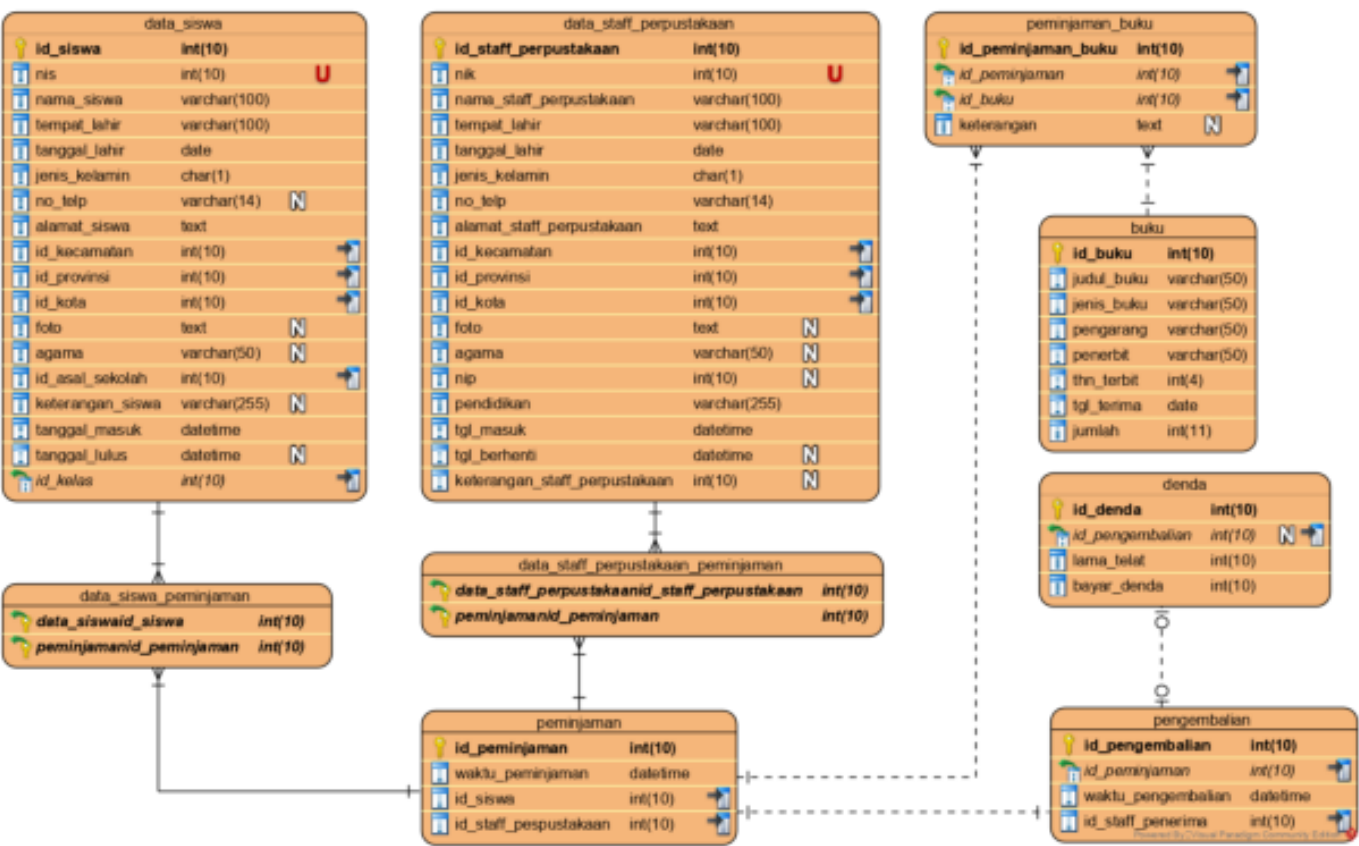

Gambar 8. Layanan Perpustakaan

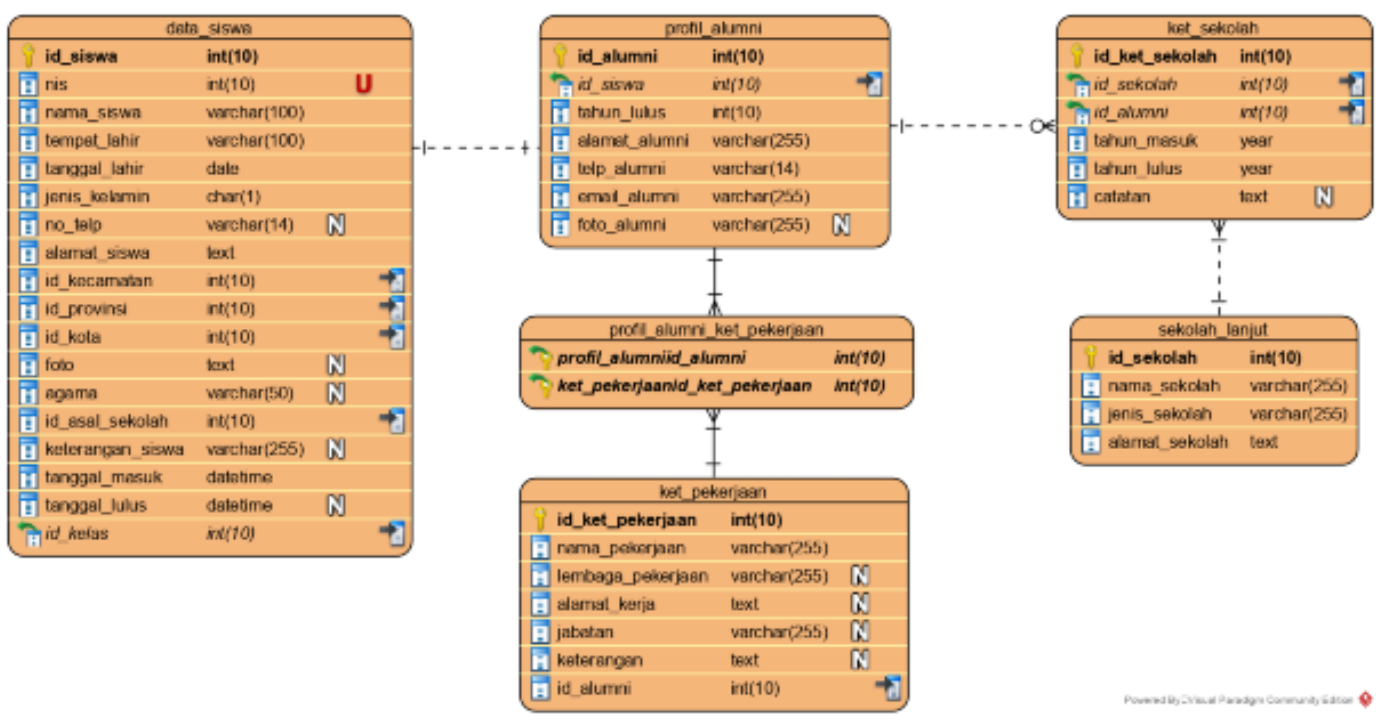

Gambar 9. Pelacakan Alumni 
Jurnal Riset Sistem Informasi Dan Teknik Informatika (JURASIK)

Volume 5 Nomor 2 Agustus, pp 175-186

ISSN: 2527-5771/EISSN: 2549-7839

https://tunasbangsa.ac.id/ejurnal/index.php/jurasik

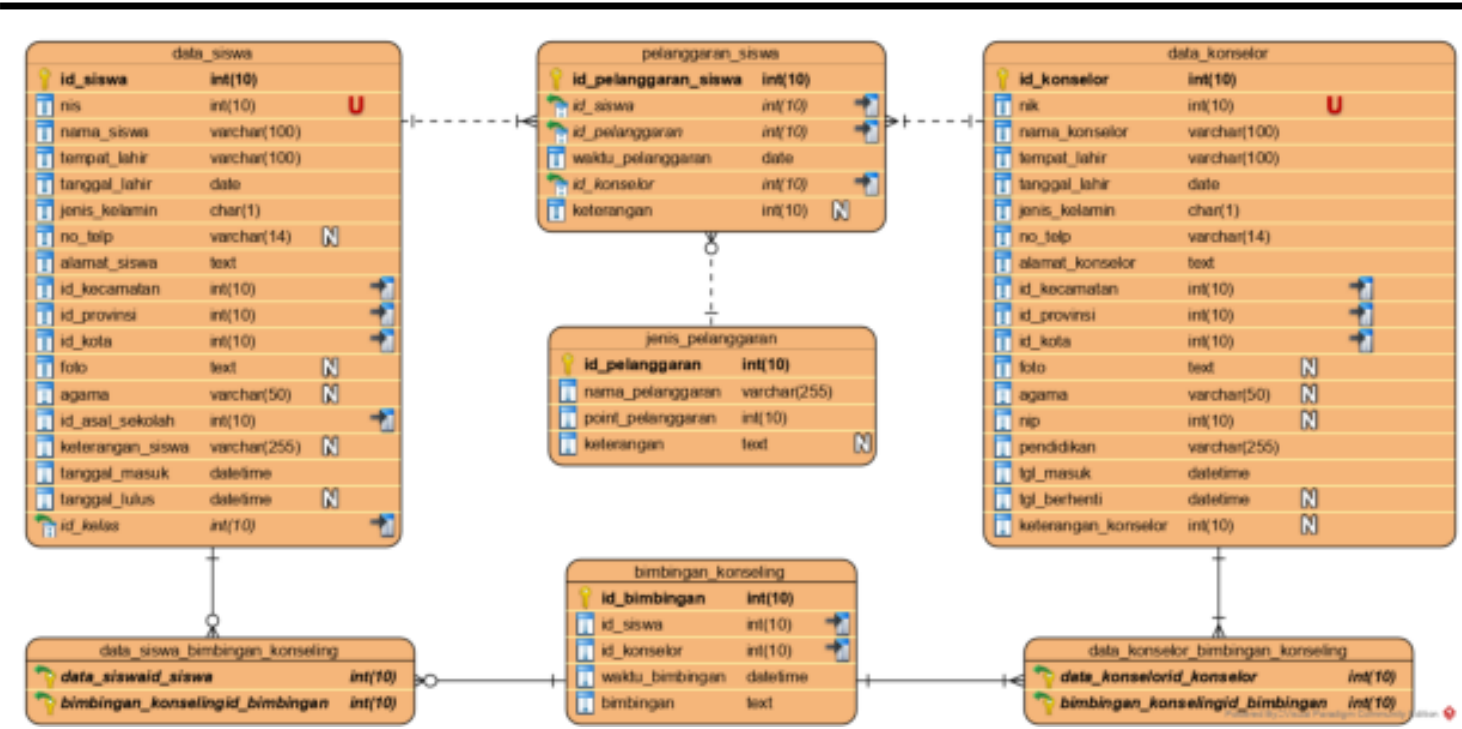

Gambar 10. Bimbingan Konseling

\begin{tabular}{|c|c|c|c|c|c|c|c|c|c|}
\hline \multicolumn{3}{|c|}{ dita_sikwa } & \multicolumn{2}{|c|}{ Sisima_olstra } & & & \multicolumn{3}{|c|}{ Gata_guru } \\
\hline id_siswa & int(10) & & id_siswa_ekstrn & int (10) & & & id_guru & int(10) & \\
\hline (1) nis & $n t(10)$ & u & if tol gabung & date & & & (1) $n \mathrm{k}$ & int(10) & $\mathbf{u}$ \\
\hline 1] narna_sswa & varchar(100) & & II tahun_ketus & date & $\mathbb{W}$ & & i] namb_aru & varchar(100) & \\
\hline II) tempar_lanir & warchar(100) & & (i) keterangin & teant & $\mathbb{W}$ & & if tempot_latir & varchar $(100)$ & \\
\hline if tangosed _lathir & date & & Tid_siswa & $n \in(10)$ & $\Rightarrow$ & & if tarosed bhir & dab & \\
\hline If jeris_kehamin & char(1) & & Tid_aletra & $\operatorname{mos}(10)$ & & & II jenis_kelamin & char(1) & \\
\hline 1] no_kip & varchar(14) & W & $v$ & & & $\frac{1}{T}$ & (i) no_kp & varchar(14) & \\
\hline If alamat_siswa & beat & & ${ }^{\circ}$ & & data _p & ambina & 11 alamat_wat_gunu & toat & N \\
\hline 11) id kocamatan & int(10) & $\rightarrow$ & : & & id_pembina & int 10$]$ & if id kecamatan & int(10) & $\rightarrow$ \\
\hline |ื. id_provitsi & int(10) & $\rightarrow$ & $\vdots$ & & ticase & introl $\quad W \rightarrow$ & 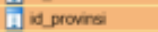 & int(10) & $\rightarrow$ \\
\hline if id kota & int(10) & $\rightarrow$ & i & & Tine elstro & $\operatorname{vin}(10) \quad \rightarrow$ & if id kota & int(10) & $\rightarrow$ \\
\hline B̂for & lext & N & \pm & & & $I$ & ดे tolo & veat & M \\
\hline f) agama & varchar (50) & W & pris eke & & & 1 & if agama & warchar(50) & N \\
\hline A] id_assal_sokolish & nt(10) & $\rightarrow$ & id_ekstra & $\mathrm{man}$ 10) & & ; & 岗 nip & int(10) & $M$ \\
\hline 1] beteraroman_siswa & varchar(255) & 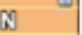 & D. nama_ckstra i & $\operatorname{rnd}(10)$ & & & (1) pendidkan & varchar(255) & \\
\hline ดี tangse_masuk & datedme & & (1) tahun_tendin of & date & & & 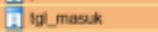 & dalketime & \\
\hline tanggid_Lus & dexesme & N & [0 tahun_thup & dale & $\infty$ & & (1) igl_bertenti & dabtime & $\omega$ \\
\hline Tidickelos & $\operatorname{mat}(10)$ & $\rightarrow$ & (6) jenis & verchar(10) & & & A keterangan guru & int(10) & \\
\hline
\end{tabular}

Gambar 11. Ekstrakurikuler

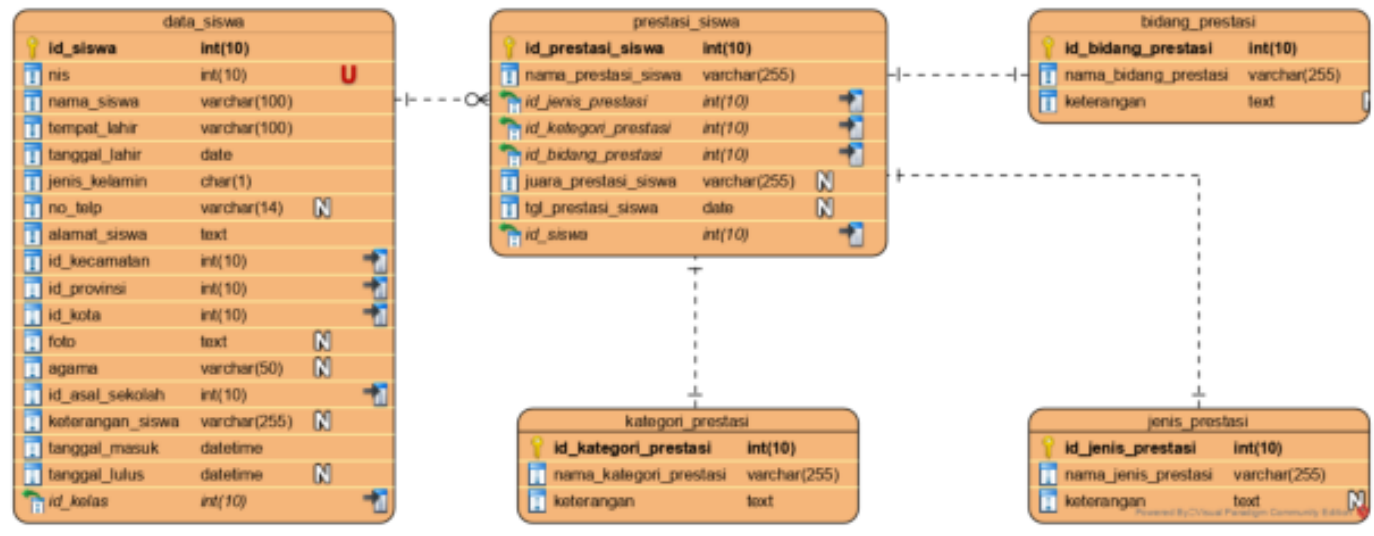

Gambar 12. Bimbingan Siswa Berprestasi 


\section{SIMPULAN}

Desain arsitektur data sudah berhasil dibuat menggunakan Entity Relationship Diagram. Adapun ERD tersebut didapat dari proses entitas-entitas proses bisnis sekolah. Proses bisnis sekolah diperolah dengan menganalisa proses bisnis yang ada dalam Standar Nasinal Pendidikan menggunakan analisa value chain. Dengan digunakannya analisa value chain tersebut didapatkan aktivitasaktivitas penting sehingga mudah dalam membuat entitas. Dengan adanya desain arsitektur data system informasi sekolah ini dapat membantu dalam pengembangan sistem informasi sekolah yang menerapkan Standar Nasional Pendidikan/ Sekolah Standar Nasional.

\section{DAFTAR PUSTAKA}

[1] M. Susanti, "Perancangan Sistem Informasi Akademik Berbasis Web Pada Smk Pasar Minggu Jakarta", Jurnal Informatiks, Vol.III No.1, Jakarta, 2016.

[2] T. Djaelangkara, R. Sengkey, A. Oktavian, Lantang "Perancangan Sistem Informasi Akademik Sekolah Berbasis Web Studi Kasus Sekolah Menengah Atas Kristen 1 Tomohon", e-jurnal Teknik Elektro dan Komputer, Manado, 2015.

[3] F. Muttaqin, M. Musadieg And Riyadi "Analisis Dan Desain Sistem Informasi Berbasis Komputer Untuk Persediaan Barang Pada Toko Bahan Bangunan", Jurnal Administrasi Bisnis (JAB), Vol. 8 No. 1, Malang, Februari, 2014.

[4] D. Puspitasari, "Sistem Informasi Perpustakaan Sekolah Berbasis Web", Pilar Nusa Mandiri, Vol. XII, No.1, Jakarta, September, 2015.

[5] J. Marisa, R. Syahni, R. A. Hadiguna dan Novialdi, "Analisis Strategi Rantai Nilai (Value Chain) Untuk Keunggulan Kompetitif Melalui Pendekatan Manajemen Biaya Pada Industri Pengolahan Ikan", Journal of Animal Science and Agronomy Panca Budi, vol. 2, no. 02, p. 10, 2017.

[6] L. Mangifera, "Analisis Rantai Nilai ( Value Chain )Pada Produk Batik Tulis Di Surakarta”, BENEFIT Jurnal Manajemen dan Bisnis, vol. 19, no. 1, p. 26, 2015.

[7] Peraturan Menteri Pendidikan Nasional Nomor 19 Tahun 2007 tentang Standar Pengelolaan Pendidikan. 